\title{
Decodificando aspectos psicosociales e ideológicos en la búsqueda de la verdad objetiva y la verdad jurídica
}

\section{Decoding psychosocial and ideological aspects in the search for objective truth and legal truth}

\author{
Víctor Montero López ${ }^{1}$ \\ Universidad Nacional Mayor de San Marcos
}

Recibido: $05-12-19$

Aceptado: $17-12-19$

\section{Resumen}

Se realizó análisis documental y de contenido de diversos textos jurídicos y epistemológicos con fines a captar las diferencias entre verdad objetiva y verdad jurídica, decodificando aspectos psicosociales e ideológicos detrás de ellas. Análisis útiles en psicología en las áreas clínica, jurídica, social, etc.

Palabras clave: Verdad objetiva; verdad jurídica; ideología.

\begin{abstract}
Documentary and content analysis of various legal and epistemological texts was carried out in order to capture the differences between objective truth and legal truth, decoding psychosocial and ideological aspects behind them. Useful analyzes in psychology in the clinical, legal, social, etc. areas.
\end{abstract}

Keywords: Objective truth; legal truth; ideology.

1 Docente asociado de la Universidad Nacional Mayor de San Marcos. E-mail: vmonterol@unmsm.edu.pe

(C) Los autores. Este artículo es publicado por la Revista de Investigación en Psicología de la Facultad de Psicología, Universidad Nacional Mayor de San Marcos. Este es un artículo de acceso abierto, distribuido bajo los términos de la licencia Creative Commons Atribucion - No Comercia_Compartir Igual 4.0 Internacional. (http://creativecommons.org/licenses/by-nc-sa/4.0/) que permite el uso no comercial, distribución y reproducción en cualquier medio, siempre que la obra original sea debidamente citada. 
Para solucionar un problema se necesita trazar un objetivo, elegir entre opciones (conocimientos y estrategias), y consecución del objetivo. Pero ante todo se debe definir bien el problema, y esto implica formularse una pregunta clave. La idea es ir hacia la verdad, pero si no se define bien el problema, eso sí que es un problema. Pero realmente esa persona querrá saber la verdad o quiere escuchar lo que le conviene. El ser humano tiene una gran capacidad de autoengaño y a veces teme la verdad, y muchos en el fondo no desean solucionar un problema. Allí intervienen mecanismos psicológicos pero también ideológicos. En la ideología no solo tenemos una distorsión de la verdad, sino inversión de la realidad, y una negación de la inversión de la realidad. Por ello, ir descifrando estos aspectos son claves en Psicología clínica, jurídica, social, etc. De los casos que he tratado he visto a veces rechazo a aquel que develó la verdad, se prefiere una mentira. Pero como bien dice el refrán "El que te adula y lisonjea, su bien y tu mal desea". El que es realmente tu amigo te dice tus verdades, pero de manera muy atinada. Es un reto para el psicólogo ir develando las verdades, aproximar a las personas a ir descubriendo y aceptándolas.

En relación al poder, algunos dicen busquemos la verdad objetiva, pero esta es percibida de diversas formas, pero más aún esta no siempre se revela o a veces nos parece que la deforma, no se acepta si esta no coincide con nuestras creencias o intereses, olvidamos que hay una diferencia con la verdad jurídica,

Ruiz (2016) investigador en epistemología del Derecho señala: "La verdad y el derecho guardan una vinculación muy estrecha, especialmente en la solución de conflictos llevada a cabo a través del proceso judicial. El juez cuando resuelve la controversia jurídica que ha conocido, tiene como base el conocimiento sobre la verdad de las proposiciones referidas a los hechos controvertidos, y adicionalmente, el conocimiento dogmático del derecho. En el primer caso, se presenta una serie de problemas a los cuales se enfrenta el juzgador, los cuales derivan del propio derecho o de la imposibilidad respecto de la reconstrucción de los hechos controvertidos tal y como acontecieron en el pasado. El control sobre esos dos obstáculos será determinante para que decisión judicial alcance un alto estándar de calidad epistemológica y jurídica, que repercuta positivamente en la generación del bien común" (pg. 6-7). "En el análisis del tema de la verdad en el derecho, no hay que adoptar una posición escéptica o relativista, sino una de tipo objetivista y de corte crítico, en la cual el jurista someta los hechos que le dan a conocer las partes en la controversia jurídica, a un estricto análisis epistemológico, gnoseológico, lógico y dogmático jurídico, complementado con su experiencia, con el fin de determinar hasta qué punto esos hechos son independientes de él, en qué medida son construcciones personales -subjetivas-, y en cuáles casos es posible o hasta qué punto pueden ser conocidos con cierto grado de objetividad (pg.8)". 
Hay que hacer una distinción entre la verdad formal o procesal y la verdad real o material, la figura de la prueba sigue una estructura que influye en lógica de la verdad (Ruiz, 2016; Taruffo, 2010).

Bertolino (2007) al analizar la "verdad jurídica objetiva" aborda la desmesura jurisdiccional que genera en la decisión del Juez un distanciamiento de los hechos acreditados durante el proceso. La "verdad jurídica objetiva" es vista desde tres ópticas: el estático, el dinámico y el casuístico." Y el Juez está obligado a considerar todas las pruebas admisibles y conducentes y aún a facilitar al acusado de la posibilidad de que aporte más pruebas que reúne esas condiciones e incluso a suministrar de oficio en su favor. (Bertolino, 2007).

Moya (2009) precisa que "existe una verdad que está en la naturaleza y que hay que ir descubriendo mediante la aplicación de técnicas cada vez más sofisticadas, y existe una verdad subjetiva que es verdadera cuando su referente externo se corresponde con una sentencia o proposición, y falsa cuando su referente externo no se adecua a la sentencia. Sin embargo, existen verdades falsas si el sujeto está convencido de que la realidad se corresponde con el contenido de su conciencia pero no es así. La neurología actual está interesada, utilizando técnicas de neuroimagen, en leer el cerebro y discriminar entre la verdad subjetiva, que se corresponde con los contenidos de la conciencia, y la verdad objetiva que en algunos casos no es consciente. Algunos experimentos llevados a cabo en lo que va de siglo aportan alguna evidencia sobre la posibilidad de leer el cerebro y discriminar la verdad objetiva y la subjetiva". Ejemplifica cómo el mismo Pilato al emitir sentencia se pregunta: ¿y qué es la verdad?, que para Vives la verdad implica conocimientos suficientes para distinguir la verdad del engaño. Descartes encontró la iluminación del espíritu de la verdad que iluminó sus investigaciones filosóficas, matemáticas, biológicas y físicas. Freud intenta develar el inconsciente pues la verdad redimiría a los sujetos traumatizados y les restituiría el equilibrio personal.

Por verdad objetiva, considera el marxismo tal contenido de nuestras representaciones que refleja exactamente la naturaleza, el universo objetivo. Nuestro conocimiento, verificado por la práctica, es verdadero y adquiere la significación de las verdades objetivas (Iudin y Rosental,1961).

El concepto de realidad objetiva se relaciona a objetos y sujetos que tienen vida material, más allá de lo que se conozca o sepa de ellos. Podemos no tener conocimiento de ello, pero la realidad objetiva existe (Pérez y Gardey, 2015). En las decisiones, en fallos diversos, hay interpretaciones de la realidad, de la verdad; u omisiones de pruebas, documentos, etc. que pueden distorsionar la realidad, interviniendo aspectos psicosociales, y hasta actos para favorecer o perjudicar a otros. 
Cervera (2017) periodista especialista en ciencia y tecnología, plantea que la verdad científica no es democrática ni puede ser hallada por la vía legal. Los tribunales no tienen por objetivo la verdad, sino la justicia. La justicia más que establecer la verdad (o falsedad) busca resolver los conflictos entre las personas.

Una acción discursiva será falsa cuando presenta, o pretende presentar, "por una buena argumentación -o al menos por mejor de lo que es-, y en esa medida se presta o induce a error, pues en realidad se trata de un seudoargumento o de una argumentación fallida o fraudulenta" (Ruiz, 2016). Así se descartan las falacias que son un argumento cuya principal característica es conducir a una persona al error (Sánchez- García (2010). Se busca que la decisión del juez tenga más calidad racional y un mayor impacto y eficacia social (Ruiz, 2016).

La verdad por correspondencia, más se adapta al proceso judicial, siendo complementada a veces por la teoría hermenéutica de la verdad (Ruiz, 2016; Nicolás y Frápolli (1997).

Morris (2002) señala en el abogado son la inducción como la deducción forman parte de su trabajo; que la incertidumbre no altera todas las relaciones jurídicas. El sistema jurídico proporciona orden en lo que de otra manera seria un mundo desordenado. Lo básico es plantear preguntas. El abogado debe encontrar respuestas. El someter los problemas jurídicos a este proceso, busca encontrar medios de prevención contra el error, y descubrir procedimientos más eficaces para obtener resultados aceptables (Reyes, 2014). Ahora, cuando buscamos solucionar un problema lo primero es definir bien el problema, y el psicólogo tiene que formular las preguntas claves para llegar a la verdad, esto nos permitirá recién trazarnos adecuados objetivos, elegir entre las opciones posibles e ir a la consecución del objetivo. Así no solo es buen profesional o estudioso el que sabe de un tema sino el que formula buenas preguntas. Pero muchas veces, la persona busca escuchar lo que le quiere y no descubrir la verdad, porque a veces esta es dolorosa y prefiere engañarse, pese a que no solucionará su problema.

Así es necesario "el estudio epistemológico de las limitaciones que tiene el juez para el conocimiento de la verdad de los hechos, que se derivan del propio del derecho, y su valoración como factores que restringen el acceso a la verdad de los hechos, y finalmente, el perfil psicológico y competencias del juzgador, como elementos determinantes para conocer los hechos en el procedimiento judicial" (Ruiz, 2016).

Blanco y Rodríguez (2007) enunciaban que se presentan distintos tipos de realidad en el humano. Realidad real relacionada a las necesidades, control, represión. Realidad victimaria vinculada a negación, carencia, muerte. Realidad fatalista que niega, que va de la objetiva social a subjetiva. Realidad epistemológica, la que busca los conceptos, problemas, teorización. Realidad trágica, que es 
conflictiva, alienada, desesperanzada. Y existe una construcción social de la realidad, como de las necesidades, los problemas, del riesgo, y de la prevención. Por ello, la tarea es decodificar este tipo de realidades en los individuos, grupos y multitudes en los que intervenimos e investigamos. Los procesos psicosociales decodificados en los países latinos nos muestran así presencia de desesperanza aprendida, fatalismo; pero también de envidia, hipocresía, chisme, violencia en algunos sectores. Y a la vez, ir decodificando procesos ideológicos detrás de estos fenómenos que nos impiden llegar a la verdad y que dan lugar a mecanismos de defensa, disonancia cognitiva, actitudes negativas, prejuicios y estereotipos que llevan a discriminación y exclusión entre los peruanos. El proceso ideológico comprende no solo la distorsión de la realidad, sino la inversión de la misma, y concluye con la negación de la inversión de la realidad. De tal manera, es común las personas inviertan la realidad al analizarla y nieguen lo estén haciendo. Es claro no quieren llegar a la verdad, el humano tienen una gran capacidad de autoengaño. Se justifica malas acciones por supuestos fines adecuados. Y se difunden falacias para justificar actos corruptos y discriminatorios. No es fácil las personas acepten sus errores como pareja, padres, hijos, amigos, compañeros de trabajo. Lo intelectual a veces sirve para camuflarse mejor. E incluso el narcisismo y la soberbia domina, pensando somos dueños de un lugar o de las personas. No es raro que surja el clientelismo, el arribismo, autoritarismo, egocentrismo y paranoia; así hasta trastornos psicológicos son presentados como virtudes. Hasta el fascismo se presenta como superador de toda ideología actualmente, y no es raro que cualquiera fácilmente asuma conductas fascistas pese a criticarlas y hasta llamarse socialista o revolucionario. El delincuente justificará sus delitos culpando a otros, el violador diciendo que la victima es la responsable por haberlo provocado, el juez o político corrupto o el que lo defiende diciendo que todos lo hacen y por tanto no es delito. Todo ello, ha generado profundo rechazo de la población a líderes e instituciones, una cultura de la desconfianza que va desde lo familiar o la pareja que usa el engaño hasta las autoridades que gobiernan. No es casual que el baile de los que sobran, las torres o triciclo Perú describan mucho mejor la realidad que diversos análisis y muchos se identifiquen con dichas canciones. Y todo se podrá borrar de nuestra mente, pero nuestros recuerdos musicales no, resisten incluso a lo ideológico, pero no son simple condicionamiento, queda en el sentimiento pero no se traduce necesariamente en lo ideológico o en opciones políticas determinadas. En lo jurídico, el psicólogo puede develar la mentira o culpabilidad, pero tiene que ponerse en el caso de la víctima y el victimario; pero la responsabilidad en la violencia, en el abuso sexual, la violación, corrupción y otros delitos, no se traducen necesariamente en sentencias, pues la verdad debe ser traducida al lenguaje jurídico; superando a la vez a las organizaciones para delinquir que incluyen hasta jueces y policías. Por ello, lo moral y ético debe ser construido desde el hogar y la escuela y hacerse hábitos de todos. 
Por tanto, si bien existen vínculos entre las realidades científica, objetiva, y subjetiva, con la realidad jurídica; estas tienen particularidades y niveles de acceso que tienen lógicas coincidentes y distintas. Si bien la verdad jurídica privilegia el llegar a la verdad, al tener que tratar sobre humanos esto complica se refleje totalmente. Un fallo podría reflejar totalmente la realidad y la verdad, haciendo justicia; pero podría no coincidir con la verdad o realidad. Por ello, hay que conocer la lógica del Derecho para aportar al descubrimiento de la verdad y la realización de la justicia. Entiendo que son diferentes lógicas que no necesariamente coinciden, en lo jurídico el texto debe ser coherente en su exposición y aunque no sea tan objetivo o real puede ser considerado válido. No basta con tener la verdad hay que traducirlo a lo jurídico. Por eso lo que aprueben los niveles de justicia no necesariamente se corresponden con la verdad. La verdad puede ser manipulada, y no faltan "pequeños Montesinos" que hagan el trabajo sucio.

Clemente $(1992,1998,2007,2010,2011)$ enunciaba diversos factores que pueden influir en la impresión que se pueden formar de una persona durante un proceso, el papel que cumplen los medios, etc. La Psicología Jurídica aporta a una mejor convivencia, a crecer en normas y valores; siendo la motivación y la persuasión claves que influyen en las normas. Así, mientras la Psicología Social estudia las relaciones interpersonales, sean reales o imaginarias; el humano es también sus sueños, sus fantasmas, etc. En cambio, el Derecho regula las relaciones sociales reales. De allí, la enorme importancia que tiene la Psicología Jurídica en su aporte al develamiento de la verdad y la justicia.

Ante lo criticable del sistema, hay apologistas de la violencia. Frente a ello, Montero $(2017,2018)$ señala que las guerras solo han traído pobreza y sufrimiento a los más pobres, que la violencia no permite progreso alguno. Arendt (1951, 1958,1972) decía: "La violencia no es la revolución, es la partera de la historia no es la creadora de la historia" (pg.32-33). En varias publicaciones sin conocer aún las afirmaciones de Arendt, he señalado que "la violencia no es la partera de la historia, sino es la historia la partera de la violencia". Pinzón (2014) analizando el idioma alemán, precisa que en El Capital, Marx (1976) describiendo las terribles y violentas condiciones históricas de la "acumulación originaria del capital" y del surgimiento del modo de producción capitalista recurre a la metáfora: "La violencia es la partera de toda sociedad vieja preñada de una nueva. Ella misma es una potencia económica". Así Pinzón, aclara que Marx "nunca escribió que la violencia es la partera de la historia, ni que la violencia fuera una fuerza ciega en sí misma o absoluta, ni menos aún que la violencia engendrara una nueva sociedad; sino que dejó bien claro su papel como ayudante- de-parto, y, le otorgó su sentido histórico como una potencia en el sentido de fuerza económica" (pg.1).

Es curioso como el dinero, la figuración, el poder decidir sobre los demás, el buscar tener liderazgo por intereses no colectivos sino intereses individualistas, etc., todo ello converge en un defecto: vanidad. Bien decía el Eclesiástes, Sagrada 
Biblia (1960): "Vanidad de vanidades, dijo el Predicador; vanidad de vanidades, todo es vanidad. ¿Qué provecho tiene el hombre de todo su trabajo con que se afana debajo del sol? Todo tiene su tiempo, y todo lo que se quiere debajo del cielo tiene su hora. Tiempo de nacer, y tiempo de morir; tiempo de plantar, y tiempo de arrancar lo plantado... tiempo de destruir, y tiempo de edificar; tiempo de llorar, y tiempo de reír...tiempo de callar, y tiempo de hablar... ¿Qué provecho tiene el que trabaja, de aquello en que se afana?...Aquello que fue, ya es; y lo que ha de ser, fue ya... Vi más debajo del sol: en lugar del juicio, allí impiedad; y en lugar de la justicia, allí iniquidad... ni tiene más el hombre que la bestia; porque todo es vanidad. Todo va a un mismo lugar; todo es hecho del polvo, y todo volverá al mismo polvo" (pg. 766).

Los principios de per se, no existen. Involucran personas. Y a veces las defienden hasta con nombre propio y en contra del país. No porque la quieras pintar diferente, esta cambiará. Como decía Romualdo (1975) "Si pintaras mi país color de rosa, serías un gran pintor para ellos"-

Una colega psicóloga apellidada Benavides en este 2019 me señalaba: "El dinero ensucia al que lo permite, al que la ambición y arrogancia lo enceguece o al falto de amor propio y dignidad que se deja comprar. El dinero solo compra a gente "barata". Además, el pueblo está harto de falta de justicia frente a la delincuencia, la violencia, las violaciones y abusos sexuales; está harta de ver cómo un delincuente que es llevado a la comisaría sale al poco rato o que los jueces ordenan su libertad; así hay barrios cansados de delincuentes ponen cartelones advirtiendo que van a linchar a los delincuentes, otros exigen la pena de muerte.

Nadie puede apoyar la barbarie, obviando los Poderes y leyes, pero que existe injusticia, jueces y abogados corruptos y que se burlan de las leyes, sobre todo en casos de abuso sexual, violaciones, asesinatos y violencia contra la mujer es evidente, contra eso yo y la gran mayoría de la población se pronuncia y protesta. Hay que recordar la doctrina de la iglesia que igual coincide en esta crítica; y por tanto debe aplicarse a la misma iglesia.

Es falaz y prejuicioso decir "las Ongs han copado el Poder Judicial" o "los caviares dominan el Poder Judicial", falso más bien si otros partidos tradicionales y nuevos tienen mucha presencia, quien no sabe las simpatías de muchos que tienen poder, y eso ha ocurrido hace muchos años. Como dijo el ex congresista Abugattas en una entrevista realizada por Canal N el 2019 "decir eso es absurdo, pues los caviares no pasan de unos 24 " y tenerle miedo a ellos es irracional", más bien estas frases si reflejan preocupación por ir perdiendo el control total del Poder Judicial, de los cambios aunque pequeños que se están dando. Aspectos por criticar siempre van a haber, pero las Ongs cumplen importante labor, debemos superar los mitos, debían recordar que la primera que tiene Ongs es la Iglesia Peruana con Ceas y 
Caritas que hacen una labor digna de todo elogio. Igualmente otras religiones tienen Ongs muy valiosas como Adra.

Otras veces, se piensa que lo definitorio es quien gana un debate, pero Parra (2016) explica cómo gente mucho menos capaz puede ganar una discusión (pg.23), caso del debate Fujimori contra Vargas Llosa. Y los discursos dogmáticos y llenos de clisés cometen este error, Nietzsche llama zafios doctos, con títulos académicos y expertos pero que fallan en erudición y les falta humildad. El autor enuncia varios problemas: 1) gente que confía demasiado en lo que dice, como el efecto Dunning-Kruger, donde se repite lo que otros dicen. "Todos somos capaces de autoengañarnos con la misma eficacia en todos los ámbitos de la vida" (pg.3). Desde la opinión sobre una persona hasta sobre un partido político. No es que algunos polemistas sean imbéciles, ni que otros fueran idiotas, sino en asumir que todos lo podemos ser en algún momento. Por eso deja que desear que un ex Presidente que se precia de ser gran orador haya tildado a sus opositores que lo acusan de imbéciles, pues esta palabra significa: idiota, retrasado, deficiente, subnormal, anormal; estúpido, tonto, lelo, memo, majadero, cretino, necio, insensato, borrico, papanatas. Lamentablemente nos gusta tener razón (efecto lago Wobegon), en el cual nos gana el narcisismo y ponemos nuestros logros como mejor que el resto; a veces nos comparamos con algunos que consideramos inferiores, para quedar mejor o "comparamos aspectos muy concretos de nuestras capacidades en los que quizás sí seamos mejores, pero luego generalizamos esa conclusión a otros aspectos en los que no lo somos tanto" (Arriaga, 2018. Pg. 3). Como explica Schulz (2015): "Muchísimos vamos por la vida dando por supuesto que en lo esencial tenemos razón, siempre y acerca de todo: de nuestras convicciones políticas e intelectuales, de nuestras creencias religiosas y morales, de nuestra valoración de los demás, de nuestros recuerdos, de nuestra manera de entender lo que pasa. Cualquiera diría que nuestra situación habitual es la de dar por sentado de manera inconsciente que estamos muy cerca de la omnisciencia" (pg. 7). Schütz (2015) busca comprender las equivocaciones. Así para él, el error es más bien un don que hasta nos pude mejorar nuestra visión, relacionarnos mejor y lograr crecer como persona. Todos nos equivocamos, el mismo Moliére decía "Me enfurece equivocarme cuando sé que tengo razón". Naturalmente, disgusta a veces no tener razón (ley de controversia de Benford, ley de Godwin). También, a veces, desconfiamos de lo que decimos o subvaloramos lo nuestro, sucediendo esto hasta en personas inteligentes. Burnett (2016), señala que la mezcla de los dos problemas enunciados acarrea en el debate o conversación profundos desastres, dice: "Hay áreas temáticas importantes, que se ven acaparadas por las diatribas apasionadas de individuos con opiniones personales infundadas, en vez de por las explicaciones más calmadas de los expertos bien informados, y nos fiamos de las personas que exponen más seguras. Johnson (2006) señala: "las personas que muestran una mayor actividad raquídea también se han acostumbrado a desconfiar 
más de sus propias opiniones porque estas cambian y evolucionan a medida que meditan sobre ellas" (pg.4).

Al escuchar y leer sobre el marxismo, escuchar que algunos lo indicaban como método para develar la realidad, decidí estudiarlo, pues influyó en Haya, Mariátegui (1930 a,b; 1971 a, b, c) y otros pensadores, así escuché clases con los profesores más calificados de las Universidades San Marcos y Católica, gracias a su sapiencia comprendí que otros muchos que hablaban de marxismo no sabían la metodología marxista pero lo asumían, desconocían el análisis basado en las abstracciones sucesivas y configuraciones cada vez más profundas, leyes a descubrir, categorías complejas, contradicciones y encadenamiento de determinaciones (Rochabrún,1976), Borísov, Zhamin y Makárova (1965), Ugarteche (1999, 2013), Pease (2013), Prado (1996, 2007, 2008), Sabiduría y Justicia (2018). Lo primero que aprendí es a no considerar la revisión de una teoría como algo negativo ni tildarlo despectivamente como revisionismo, sino encontrar lo positivo de este, el ser crítico ante una obra; también a recoger los aportes de diversos autores al marxismo, toda teoría debe ser enriquecida y actualizada, superar el dogmatismo y fundamentalismo; a no sacralizar una teoría ni hacer culto a la persona. Encontré por ejemplo que algunos trotskistas desconocían muchos aspectos de la vida y obra de Trotsky, e igual sucedía con otros marxistas.

Leí atento a marxistas con pensamiento propio como Gramsci (1948), Lukács (1966). Uno de ellos era Bernstein, un clásico de la literatura política e ideológica que da un ejemplo de cómo no ser dogmático, aunque el ambiente que rodea al marco teórico al que adhiere sí lo sea. Bernstein $(1982,1989)$ se arriesgó a pensar diferente basado en supuestos neokantianos y pragmáticos extraídos de la información disponible sobre el desarrollo capitalista de su tiempo, confrontados con las hipótesis de Marx. De todo esto se pueden extraer lecciones válidas para cualquier coyuntura. Para Bernstein (1989) la dictadura del proletariado era un atavismo, la meta y el medio de lucha de la clase obrera era la democracia, y pensaba que no existía "ninguna idea liberal que no pertenezca también al bagaje ideológico del socialismo". Bernstein (1989) muestra el error de creer que solo lo materialista o económico definen el marxismo; pues es claro que no solo actúan fuerzas económicas. ¿Hasta qué punto se puede reducir todo a la plusvalía? y las luchas no solo se dan entre clases, sino al interior de las mismas clases. Y la violencia no siempre es una necesidad para alcanzar los cambios. ¿Hasta qué punto todas las predicciones marxistas se han cumplido? Hay cambios en las clases. Los sucesos recientes en España, Chile, Ecuador. Bolivia, nos replantean la idea de clase política, de democracia, liberalismo y socialismo; exigen cambios en las concepciones.

Ahora si bien, no todos, tanto en la derecha e izquierda se dio el maximalismo, la tendencia a mantener ideas o actitudes extremas, especialmente en política. Sin 
haberse dado una real autocrítica en ninguno de estos, surgen más bien nuevos radicalismos.

Es polémico decir que en el Perú existe una "cultura psicopática", más bien si estamos en camino a una sociedad perversa, y algunos ambientes son muy tóxicos; esto porque muchas normas no se cumplen y terminan siendo normas perversas; es sí muy generalizado el incumplimiento de normas, el obviar el derecho del otro por conseguir un objetivo; los comportamientos en los vehículos públicos donde la violencia es impresionante o también son comunes casos como cuando alguien pasa por un crucero peatonal y un auto acelera para que el peatón corra, desconociendo hasta lo elemental que significa un crucero peatonal; cuando muchos choferes cruzan estando el semáforo en luz roja, etc., conductas que en otros países son consideradas un crimen; igual cuando se detiene un vehículo para descargar materiales para algún lugar y bloquea el tránsito importándoles muy poco lo que ocasiona, y mil casos de lo que es común se comente "todo el mundo quiere pasarse de vivo", hasta casos más graves pero que se han vuelto comunes como las expresiones de corrupción, racismo, acoso escolar entre pares, acoso laboral, acoso y abuso sexual, violaciones, feminicidios, asesinatos familiares, maltrato infantil y familiar, o dárselas de humanitario y sacrificar a su familia.

Lo más grave es que diversos profesionales adoptan también conductas psicopáticas y perversas, cometiendo estos delitos; otros apoyan estos delitos con informes parcializados. Algunos abogados parecen olvidar su principio "Orabunt causas melius" o "sólo defenderé causas justas", so pretexto de la presunción de inocencia vemos todo un numeroso grupo presto a defender como dicen algunos bajo el lema "retroceder nunca, rendirse jamás" casos de delincuencia, corrupción, delitos sexuales y otros que son evidentes. Ignoran los enormes daños mentales que sufren las víctimas sobre todo niños.

Por supuesto que son perversas también conductas como permanecer en el cargo él o ella misma o a través de otros indefinidamente. El bloquear a quien le hagan sombra. En los concursos favorecer a sus allegados, afectar en su derecho a otros, o hacer informes o licitaciones amañados, ignorar algunos principios jurídicos, hacer lo que no establece la ley. Atentar contra el empleo, el ascenso, los títulos profesionales es maldad; atenta contra derechos claves y constituyen delitos en lo administrativo, civil y penal.

Como dice Venturo (2016) se trata también de ser coherente en la vida cotidiana, no criticar o dar discursos radicales, y a la par coimear, favorecer a los amigos, evadir impuestos, que explota a sus empleados, que discrimina para ingresar a playas o barrios, que es hipócrita, que se acomoda, que se estaciona dónde quiere, que no reclama sus derechos, que es racista o discriminador, que reconoce errores y culpa a otros, que es amigo solo por interés, que se dedica 
al raje, arrogante y soberbia. Agregaría que, toca el claxon por gusto mostrando estrés, que menta la madre a cada rato; que es chismosa, envidiosa, hipócrita, violenta.

Igualmente, los pobres y culturas son excluidas de la justicia, pero también existe problemas con actitudes machistas que favorecen a agresores de la mujer; y hasta los niños y niñas son excluidos pues se los somete a largos juicios cuando denuncian una violación o un abuso sexual, cuando su palabra y los exámenes psicológicos son suficientes para condenar a los agresores y con fuertes penas.

El libro en homenaje a Max Hernández (Saba, Peralta, y Fatule, 2018), se denomina como el bolero "En el juego de la vida" cuya letra dice: "En el juego de la vida, juega el grande juega el chico, juega el blanco y juega el negro, juega el pobre y juega el rico. En el Juego de la vida, nada te vale la suerte, porque al fin de la partida gana el albur de la muerte. Juega con tus cartas limpias en el juego de la vida, al morir nada te llevas; vive y deja que otros vivan. Cuatro puertas hay abiertas al que no tiene dinero, el hospital y la cárcel, la iglesia y el cementerio". De la Puente (2018) dice Hernández aporta al conocimiento de nuestra pluralidad, multiculturalidad e identidad, que se apertura a lo diverso. Aquí es clave el ejercicio ciudadano que nos permite construir y asimilar la igualdad, que los cambios deben ser sobre todo mentales (Hernández, 2012). Bruce (2018) señala es un psicoanálisis peruano, es decir interdisciplinario y con capacidad de asombro. Esto es importante, porque la soledad también se relaciona con la psicoterapia. Teresa Bolaños anota: "Aceptar nuestra soledad nos permite aceptar nuestro dolor y poder tolerar y comprender la experiencia de la soledad y dolor del paciente" (Tsang, 2018). Hernández, (2016) dice: 'En el 'setting' se da el encuentro de dos soledades'...'Procesos de cambio que pueden darse si y solo si el paciente sabe que está solo'. En varios momentos del análisis de otro terapeuta, ante experiencias de frustraciones y desencuentros, Max decía: 'Solo como el sol". La soledad es vivencia, encuentro y más aún de nuestro tiempo.

Los valses y boleros revelan mucho de la percepción de la vida, como lo muestra una investigación (Montero, 2017). Se diría que el bolero "Oh humanidad" también se refiere a lo que tratamos, la relatividad del dinero y el poder, al decir: "Al pasar el tiempo veo, las dos tumbas cómo están, no hay nadie en el mausoleo y en la fosa solo el can". Es decir, la soledad del poderoso. Curiosamente, los dos boleros mencionados estaban dentro de los menos preferidos en el estudio mencionado. Igual es con los tangos, bien dice "Yira": "Cuando estén secas las pilas de todos los timbres que vos apretás...verás que todo es mentira, verás que nada es amor, que al mundo nada le importa" Y no falta un reggaetón como "Soledad" que diga: "Ella se sentenció a soledad por vida eterna, a todo se negó por miedo al dolor... Hoy sufre arrepentida, llora sol a sol, a nombre del 
cobarde que la traicionó, al sucio, mentiroso que me la engañó y sueño le vendió sin valorarle". Soledad del poderoso o del que poderoso no lo es, igual es.

Ser psicólogo exige tener empatía, como ponerse en los zapatos del otro, pero como dice la película "Zapatero a tus zapatos": "Es un privilegio caminar en los zapatos de otro, pero también es una responsabilidad".

Un psicólogo es un especialista en solucionar conflictos, no puede buscar que otros solucionen sus conflictos; menos pueden estar en juicios, ni denunciar por gusto, ni atacar al colega, ni trabar a alguien su desarrollo. Como decía un colega, se debe partir de rectificar errores. La cuestión es reconocer errores, porque si no se reconoce no se acepta, si no se acepta no hay voluntad de cambio, si no hay voluntad de cambio no hay gestión de cambio, y por lo tanto no se crece.

\section{CONCLUSIONES}

Develar la realidad, y la búsqueda de la verdad sigue complejos procesos donde hay que descubrir distintos tipos de realidades e ir descifrándolas, pero hay que tener claro la lógica de la verdad objetiva asumiendo una posición científica y epistemológica, como de la verdad jurídica. Tarea complicada del psicólogo jurídico de traducir una verdad en la otra, y un reto para el abogado de ser consecuente con la verdad, y también para el clínico al ver casos y para el social al trabajar con grupos. Nuestra actividad requiere el ir decodificando los procesos psicosociales e ideológicos para acércanos a ir revelando la realidad e ir descubriendo verdades, comprendiendo al otro en sus dimensiones.

\section{REFERENCIAS}

Arendt, H. (1951). Los orígenes del totalitarismo. Trad. de Guillermo Solana. Madrid: Traducción reeditada por Alianza Editorial, 2006, con prólogo de Salvador Giner.

Arendt, H. (1958). La condición humana. Trad. Ramón Gil. Barcelona: Paidós.

Arendt, H. (1972). Verdad y mentira en la política, Barcelona: Página Indómita, 2017.

Arriaga, A. (2018). 15 fenómenos psicológicos inconscientes que distorsionan nuestra percepción. http://comecocoscuv.blogspot.es/tags/fenomenos/

Bertolino, P. (2007). La Verdad Jurídica Objetiva. Segunda edición, Revisada, Ampliada y Actualizada, LexisNexis, Buenos Aires, 2007.

Bernstein, E. (1982). Problemas del socialismo. El revisionismo y socialdemocracia. México: Siglo XXI.

Bernstein,E.(1989).LasPremisasdelSocialismoylas TareasdelaSocialdemocracia.Madrid: Fundación de Análisis e Iniciativas Socialdemócratas.

Bruce, J. (2018). En el juego de la vida. Lima: La República. https:/larepublica.pe/ politica/1381645-juego-vida/ 
Blanco, A. y Rodríguez, J. (2007). Intervención psicosocial. Madrid: Pearson.

Borísov, Zhamin y Makárova (1965). Diccionario de Economía Política. URSS: Progreso.

Burnett, D. (2016). El cerebro idiota. Madrid: Planeta.

Cervera, J. (2017). Verdad científica y verdad jurídica. En Frontera Cuaderno de Cultura Científica. https://culturacientifica.com/2017/11/09/verdad-cientifica-verdadjuridica/

Clemente, M. (1992). Psicología Social Aplicada. Madrid: Eudema.

Clemente, C. (1998). Fundamentos de la Psicología Jurídica. Madrid: Pirámide.

Clemente, C. (2007). Psicología Jurídica. La Coruña: Universidad de la Coruña.

Clemente, C. (2010). Psicología Jurídica. Madrid: Pirámide.

Clemente, C. (2011).Fundamentos y principios de Psicología Jurídica. Madrid: Pirámide.

De la Puente, J. (2018). Los años de Max Hernández. Lima: Diario La República, 21 diciembre 2018 https://larepublica.pe/politica/1379977-anos-max-hernandez

Gramsci, A. (1948). El materialismo histórico y la filosofía de Benedetto Croce. Buenos Aires: Nueva Visión.

Hernández, M. (2012). En los márgenes de nuestra memoria histórica. Lima: Fondo Editorial de la USMP.

Hernández, M. (2016). De la intimidad. Revista de Psicoanálisis No. 17. Lima: Sociedad Peruana de Psicoanálisis.

Iudin, P. y Rosental, M. (1961). Diccionario de filosofía y sociología marxista. La Habana: Orbe.

Johnson S. (2006). La mente de par en par. Madrid: Turner.

Luckács. G. (1966). Obras Completas. México: Grijalbo

Mariátegui, J. (1930a). Obras completas. Lima: Amauta.

Mariátegui, J. (1930b). La inteligencia y el aceite de ricino. En La Escena contemporánea. Lima: Amauta.

Mariátegui, J. (1971a). Defensa del marxismo, Obras completas, Vol. 5. Lima: Amauta.

Mariátegui, J. (1971b). Ideología y política, Obras completas, Vol. 13. Ed. Amauta.

Mariátegui, J. (1971c). Peruanicemos al Perú, Obras completas, Vol. 11. Ed. Amauta.

Marx, K. (1976). El Capital. URSS: Progreso.

Montero, V. (2017). Metodología de análisis psicosocial de medios de comunicación. Mauritus: Editorial Académica Española.

Montero, V. (2018). Problemas psicosociales en el Perú. Mauritus: Editorial Académica Española.

Morris, C. (2002). Cómo razonan los abogados. México: Limusa. 
Moya, J. (2009). La verdad objetiva y subjetiva. file:///C:/Users/HP/Downloads/DialnetLa Verdad Objetiva y Subjetiva-3094397.pdf

Nicolás, J. y Frápolli, M. (1997). Teorías actuales de la verdad, Diálogo Filosófico 38 (1997): 148

Parra, S. (2016). ¿Por qué la gente más estúpida que tú es capaz de ganarte en una discusión? https://www.yorokobu.es/gente-estupida/

Pease, H., Romero, G. y Ato del Avellanal, P. (2013). La Política en el Perú del siglo XX. Lima: Fondo editorial PUCP.

Prado, R. (1996). Mariátegui y la cuestión del "pensar bien". Revista del pensamiento marxista.

Prado, R. (2007). El marxismo de Mariátegui. Lima: Mantaro.

Prado, R. (2008). El concepto de ideología en Marx. Lima: Mantaro

Pérez, J. y Gardey, A. (2015). Definición de: Definición de realidad objetiva. https:// definicion.de/realidad objetiva.

Pinzón, A. (2014). La partera de la nueva sociedad. http://rebelion.org/noticia. php?id=188555

Reyes, M. (2014). Análisis de la obra Cómo razonan los abogados. https://www. monografias.com/ trabajos96/analisis-obra-como-razonan-abogados/analisis-obracomo-razonan-abogados.shtml

Romualdo, A. (1975). Edición extraordinaria. Poema Color de rosa. Lima: Mejía Baca.

Ruiz, J. (2016). La verdad en el Derecho. México: Revista Intersticios sociales 12, Zapopan setiemb.

Sagrada Biblia (1960).El Eclesiástes 1, 2, 3. Reina-Valera, Sociedades Bíblicas en América Latina. 1960.

Rochabrún, G. (1976). ¿Hay una metodología marxista? Lima: Universidad Católica.

Sánchez García, F. (2010). Paralogismos y sofismas del discurso político español. La falacia politica en un corpus de debates parlamentarios, Anuario de Estudios Filológicos 33 (2010): 274.

Saba, Peralta y Fatule: En el juego de la vida. Lima: Ed. Gradiva.

Sabiduría y Justicia (2018). Entrevista a Raymundo Prado. https://www.youtube.com/ watch?v=xDQ0crXez0s

Schulz, K. (2015). En Defensa del Error: Un ensayo sobre el arte de equivocarse. Madrid: Siruela.

Tsang, J., (2018). Max Hernández Camarero es homenajeado en el libro "En el juego de la vida". Lima: Diario El Comercio, 12 diciembre. https://elcomercio.pe/luces/libros/ impreso-max-hernandez-camarero-homenajeado-libro-juego-vida-noticia-590287.

Taruffo, M. (2010). Simplemente la verdad. Madrid: Marcial Pons. 

jurídica

Ugarteche, O. (1999). El falso dilema. América Latina en la economía global, Lima Caracas, Fundación Ebert, Nueva Sociedad, 1997, segunda impresión 1999

Ugarteche, O. (2013). La Gran Mutación. El capitalismo real del siglo XXI. México: IIEC UNAM

Venturo, S. (2016). Para mis amigos todo, para mis enemigos la ley. Diario Perú 21, 2 febrero.https://peru21.pe/opinion/sandro-venturo-mis-amigos-mis-enemigos-ley 211304 
